\title{
Robotik Uygulamalar İçin Prizmatik Kesitli Millerin Burulması Esasına Dayanan Elastik Eyleyici Tasarımı
}

\author{
Murat Reis \\ Makine Mühendisliği Bölümü, Mühendislik Fakültesi, Bursa Uludağ Üniversitesi, Türkiye (ORCID: 0000-0001-5853-488X)
}

(Bu yayın HORA kongresinde sözlü olarak sunulmuştur.)

(İlk Geliş Tarihi 1 Ağustos 2019 ve Kabul Tarihi 24 Ekim 2019)

(DOI: $10.31590 /$ ejosat.637631)

\begin{abstract}
ATIF/REFERENCE: Reis, M. (2019). Robotik Uygulamalar İçin Prizmatik Kesitli Millerin Burulması Esasına Dayanan Elastik
\end{abstract} Eyleyici Tasarımı. Avrupa Bilim ve Teknoloji Dergisi, (Özel Sayı), 146-151.

\begin{abstract}
$\ddot{O} \mathbf{z}$
Eyleyiciler herhangi bir robotik sistemin genel performansını belirleyen en önemli bileşenlerdir. Uzun yıllar boyunca, uygun eyleyicilerin eksikliği, hareket, güvenlik ve enerji verimliliği açısından canlı organizmalarla rekabet edebilecek yüksek performanslı makinelerin veya robotların gelişmesini engellemiştir. Biyolojik sistemlerin çevresel değişkenlere adaptasyon özellikleri; Örneğin, değişken sertlik özelliklerine sahip biyolojik kasın kontrol performansı, mekanik cihazların performansını aşmaktadır. Elastik eyleyicilerin değişken rijitlik özellikleri, endüstriyel robotlarda kullanılan konum hassasiyeti gerektiren geleneksel rijit eyleyicilerin çalışma prensibinden oldukça farklıdır. Son yıllarda elastik eyleyicilerin tasarımı üzerine çok sayıda çalışma yapıllmış olmasına rağmen, yaygın olarak kullanılan basit rijit servo eyleyiciler yerini alabilecek düşük maliyetli ve kompakt bir elastik eyleyici henüz mevcut değildir. Bu çalışmada, düşük maliyetli olması nedeniyle robotik uygulamalarında ve hobi araçlarında çok yaygın olarak kullanılan standart bir servo motor, dişli sistemine eklenen elastik bir kavrama vasıtasıyla sertliği değişstirilebilir bir eyleyiciye dönüştürülmektedir. Elastik kavrama, silindirik diskin üzerine yerleştirilmiş prizmatik kesitli dört küçük yayrak yaydan oluşmakta ve eyleyicinin sertliği, prizmatik yayların (millerin) kavrama uzunluğunu değiştirerek ayarlanmaktadır. Çalışmada, bu yenilikçi tasarım tanıtılmış, ardından prizmatik milin burulma rijitliğinin kavrama uzunluğu ile değişimini ifade eden denklemler ve bu denklemlerin çözümleri verilmiştir.
\end{abstract}

Anahtar Kelimeler: elastik, eyleyici, robot, servo, kavrama, mil.

\section{Elastic Actuator Design Based on Torsion of Prismatic Shafts for Robotic Applications}

\begin{abstract}
Actuators are the most critical components that determine the overall performance of any robotic system. For many years, the lack of suitable actuators has hampered the development of high-performance machines or robots that can compete with living organisms in terms of motion, safety, and energy efficiency. Adaptation properties of biological systems to environmental variables; for example, the control performance of biological muscle with variable stiffness properties exceeds the performance of mechanical devices. The variable stiffness characteristics of elastic actuators are quite different from the operating principle of conventional solid actuators that require accurate reference trajectory tracking used in industrial robots. Although there has been a lot of work on the design of elastic actuators in recent years, a low-cost and compact elastic actuator that can be used in place of standard rigid servo actuators is not yet available. In this study, a standard servo motor, which is widely used in robotic applications and hobby vehicles due to its low cost, has been transformed into an elastic actuator by an elastic coupling attached to the gear system. The elastic coupling consists of four small shafts with a prismatic cross section placed on the circular disk, and the stiffness of the actuator is adjusted by varying the clutch length of the prismatic shafts. In the study, this innovative design is explained, then the equations expressing the variation of the torsional stiffness of the prismatic shaft with the coupling length and solutions of these equations are given.
\end{abstract}

Keywords: elastic, actuator, robot, servo, clutch, shaft. 
European Journal of Science and Technology

\section{Giriş}

Geleneksel robotlar hareketi sağlamak ve çevreleriyle etkileşime geçebilmek için sert eyleyicileri ve sert bağlantıları kullanmaktadır. Bu durum yüksek konum hassasiyeti gerektiren üretim robotları ve tıp alanında kullanılan operasyonel robotlar için gerekli bir durum iken, bacaklı ilerleme mekanizmaları ve mobil robotlar için enerji tüketim değerini artıran bir faktör olarak karşımıza çıkmaktadır. Zira sert eğleyiciler tarafından tahrik edilen bir bacaklı ilerleme mekanizması hareket esnasında dinamik şok yüklerine maruz kalacağından harekatleri oldukça yavaş ve enerjik olarak oldukça verimsizdir. Buna karşın canlılar kas ve tendon yapılarının sertliğini ilerleme esnasında aktif olarak değiştirilebilirler. Bu sayede bacaklarını elastik bir uzuv gibi kullanarak yüksek hızlı hareketlerinde vücut yapılarını bu şok yüklerinden korur ve dahası yerden gelen tepti kuvvetinin etkisini elastik vücut elemanlarında depolayarak bir sonraki adımda bu potansiyel enerjiyi kinetik enerjiye dönüştürür ve ilerlemek için robotlara kıyasla çok daha az enerjiye ihtiyaç duyarlar.

Değişken sertlik özellikleri, endüstriyel robotlarda kullanılan yüksek konum hassasiyeti ve kesin yörünge takibi gerektiren geleneksel sert eyleyicilerin performansından oldukça farklıdır (Vanderborght vd., 2012) ve bu bakımdan elastik eyleyiciler daha ziyade bacaklı robotlar için umut vadetmektedir. Zira elastik eyleyiciler sayesinde günümüz robotları, her ne kadar hala yüksek enerji tüketimine sahip olsalar da, neredeyse canlılar kadar doğal hareketler yapabilmektedirler. İdeal bir elastik eyleyicide hareket esnasında ortaya çıkan enerji elastik elemanlar tarafından depolanmalı ve depolanan enerjinin tamamı kayıpsız olarak işe dönüştürülebilmelidir. Eyleyicinin sertliği enerji tüketimi olmaksızın değiştirilebilmeli, sertlik değişism oranı mümkün olduğu kadar geniş olmalı, sertlik ve pozisyon kontrolü birbirinden bağımsız olarak yapılabilmelidir.

Son yıllarda bu alanda pek çok bilimsel yayın ortaya konmuş ve farklı elastik eyleyici tasarımları geliştirilmiştir. Bu eyleyicilerin, beş ana sertlik kontrol yöntemi temelinde tanımlandığı genel bir sınıflandırması Van Ham vd. (2009) tarafından sunulmuştur. Bu sınıflandırmanın revizyonu Vanderborght vd. (2013) tarafından yapılmıştır. Sertliği değiştirilebilir eyleyicilerin ilki seri elastik eyleyici olarak adlandırılan eyleyici grubudur. Seri elastik eyleyicilerde yaya seri olarak bağlanmış bir motor yayların denge konumunu düzenleyerek çıkış kuvvetini ayarlamaktadır. Burada sertlik, pasif olarak sertliği sabitlemek yerine güç kanunu kullanılarak aktif olarak değiştirilmektedir. Motor konumu, yayın gerginliğini veya sıkışmasını değiştirmek için yayın sapmasına bağlı olarak ayarlanmaktadır (Pratt \& Williamson 1995). Migliore ve arkadaşları iki lineer yay kullanılarak antagonist düzene sahip bir tasarım oluşturmuşlardır. Bu tasarımda sertlik ayarı, iki farklı seri elastik eyleyicinin dönel bir bağlantıyı karşılıklı olarak tahrik etmesi ile sağlanmaktadır. Motorlar aynı yönde döndüğü zaman denge pozisyonu değişmekte olup motorlar zit yönde döndüğü zaman ise sertlik değiştirilebilmektedir (Migliore vd., 2005).

Antagonisttik etkileşim ile düzenlenen eyleyici tasarımına bir başka örnek de Tonietti vd. (2005) tarafından oluşturulmuştur. Bu tasarım, çapraz bağlı düzenleme ile oluşturulmuş antagonist bir tasarımdır. Yaylarla gerilen ve kayışla birbirine bağlı üç makaraya sahip olan bu eyleyici, bağlantı sertliği değişken ve kontrol edilebilen kompakt bir eyleyicidir. Bu tasarım daha kompakt olması, hızlı ve devamlı bir şekilde sertliği değiştirilebilmesi gibi avantajlara sahiptir. Fakat bu eyleyicinin kontrolü non-lineerlikten dolayı daha karmaşıktır. Hurst vd. (2004) tarafından geliştirilen tasarımda sertlik ve denge pozisyonu bağımsız olarak kontrol edilebilmektedir. Bu tasarım iki adet motora sahip olup, motorlardan biri ön gerilmeyi değiştirerek sertliği ayarlarken, diğer motor yayın denge pozisyonunu kontrol etmektedir. Bu durum eyleyicinin kontrolünü daha kolay yapmakta ve denge pozisyonunu daha hızlı değiştirirken sertliği daha yavaş değiştirme gibi özel uygulamalar için ayrı ayrı motor tasarımına izin vermektedir. Bu tasarımın en büyük dezavantajı kullanılan kablo ve makaralar nedeniyle oldukça karmaşık olmasıdır. Jack spring mekanizması olarak bilinen bir diğer tasarımda yayların aktif bobin sayısını değiştirilerek yay sertliği kontrol edilmektedir. Elastik eleman olarak helisel bir yay kullanılan bu sistemde sertlik ayarı yayda kullanılan aktif bobinlerin sayısı azaltılarak veya arttırılarak gerçekleştirilmektedir (Hollander vd., 2006). Van Ham vd. (2007) bir eksen etrafında dönen ve birbirine yay ile bağlı üç uzuvlu bir elastik eyleyici tasarımı geliştirmiştir. Bu tasarımda dengeyi ayarlamak için hareket kolunun pozisyonu kontrol edilmektedir. Bu sayede lineer bir tork-açı karakteristiğine sahip, pozisyon ve sertlik kontrolü bağımsız olarak yapılabilen bir tasarım ortaya konulmuştur. Wolf \& Hirzinger (2008) tarafından geliştirilen kompakt yapıya sahip bir tasarımda sertlik kam mekanizması yardımıyla değiştirilmektedir. Jafari vd. (2010) tasarımında sertlik kontrolünü dönme mafsalı üzerine yerleştirdiği lineer yayların konumunu merkeze yaklaştırıp uzaklaştırarak ve bu yolla yayların karşı momentini değiştirerek sağlamaktadır. Tasarımda iki yayın uzunlukları toplamı her zaman sabittir. Bu nedenle sertlik kontrol edilirken ön gerilme değişmemektedir. Çıkış kolu denge pozisyonundayken yaylar tarafından üretilen kuvvet sertliği değiştirmek için gereken yer değiştirmeye diktir. Kol denge konumunda değilse yay tarafından üretilen kuvvet yer değiştirmeye paralel küçük bir bileşene sahiptir ve sertlik kontrolü az miktarda enerji gerektirmektedir. Bu tasarımın daha yeni bir versiyonunda bu kez yay ve kuvvet noktaları sabit kalırken pivot noktasının pozisyonu değiştirilmektedir. Bu tasarımdaki en büyük avantaj pivot noktası, yay noktasına ulaştı̆̆ında sertlik sıfır olurken kuvvet noktasıyla çakıştığında ise sonsuz değere kadar artabilmesidir (Jafari vd., 2011). Bunların dışında da farklı elastik eyleyici tasarımları mevcuttur (Catalano vd., 2011, Quy vd., 2011, Lee vd., 2017) ki bu çalışmaların tamamında amaç yüksek modülerlik, küçük boyut ve düşük maliyettir.

Bu çalışmada çok yaygın bir kullanım alanına sahip olan standart bir servo eyleyici boyutları değiştirilmeden sertliği değiștirilebilir bir eyleyiciye dönüştürülmektedir. Geliştirilen tasarım özellikle bacaklı robotların enerji verimli hale getirilmesine imkân sağlayabilecek bir tasarımdır. Sertlik değiştirme ayar vidası yardımıyla manuel manuel olarak gerçekleştirilmektedir. Çalışmada ilk olarak tasarımın çalışma ilkeleri tanıtılmış ve matamatiksel olarak model oluşturulmuştur. Geliştirilen basitleştirilmiş model üzerinden yapılan analitik hesaplar ve bu hesaplamaların grafiksel sonuçları ile tasarım değişkenlerinin eyleyicinin sertliğine etkisi gösterilmiştir. 


\section{Tasarım ve Matematiksel Model}

Elastik eyleyici standart bir robot servosu üzerinde değişiklik yapılarak geliştirilmektedir. Geleneksel sert bir eyleyici olan ve robotikten, hobi araçlarına kadar pek çok alanda kullanılan standart robot servosunun ebatları değiştirilmeden sertliği değiştirilebilir bir eyleyici haline getirmek amaçlamaktadır. Bu sayede mevcut robot platformlarında herhangi bir tasarım değişikliğine ihtiyaç kalmaksızın elastik eyleyicinin bu sistemlere uygulanması mümkün olacaktır. Bu amaçla Şekil 1 de temel bileşenleri gösterilen servo motor sistemi referans olarak alınmıştır. Analog (potansiyometre kontrollü) veya dijital (enkoder kontrollü) robot servo eyleyiciyi sertliği değiştirilebilir bir eyleyici haline getirebilmek için öncelikle servo eyleyicinin mekanik yapısı ve çalışma prensibi incelenmemiştir. Standart robot servoları (eyleyicileri) çıkış miline bağlı analog veya dijital ölçüm aygıtı sayesinde istenilen açısal pozisyona yönelebilen basit mekatronik elemanlardır. Rijid servo eyleyiciler, istenilen pozisyona yönelmelari ve yeni bir komut gelmediği sürece bu pozisyonlarını muhafaza etmelari amacıyla tasarlanırlar. Servo eyleyicilerin içerisinde eyleyicinin hareketini sağlayan bir DC motor bulunmaktadır. Bu motorun dışında bir dişli mekanizması, çıkış miline bağlı bir potansiyometre (veya enkoder) ve bir motor sürücü devresi bulunmaktadır. Potansiyometre veya enkoder, motor milinin dönüş açısını ölçmektedir. Servo eyleyici içerisindeki DC motor ve buna bağlı dişli sistemi hareket ettikçe potansiyometre çıkış mili ile birlikte dönmekte ve kontrol devresi eyleyicinin bulunduğu pozisyon ile istenilen pozisyonu karşılaştırarak motoru sürme işlemini yapmaktadır. Standart robot servoları diğer eyleyiciler gibi harici bir motor sürücüye gereksinim duymadan çalışmaktadır. Şekil 1'de bir servo eyleyicinin bileşenleri gösterilmektedir.

Tasarıma standart servo eyleyici bilgisayar ortamında modellenerek başlanmıştır. Sertliği değiştirilebilir bir eyleyici mekanizması oluşturmak için momenti DC motordan çıkış miline aktaran ve Şekil 1'de ok yardımıyla gösterilen son dişli elastik eleman yerleşimi için seçilmiştir. Öncelikle çıkış dişlisinin momenti aldığı ve momenti ilettiği bölümler ayrılarak şekilde gösterildiği gibi iki parça haline getirilmiştir. Bu iki parça arasına elastik kavrama elemanları (dört adet yaprak yay) eklenerek rijit olmayan bir bağlantı kurulmuştur. Yaprak yaylar servo eyleyicinin ebatlarını değiştirmeme kriteri göz önünde bulundurularak boyutlandırılmıştır. Yaprak yay kullanımındaki ana hedef sertliği değiştirmek için yay ön gerilmesini ya da iletim oranını değiştirmek yerine yay karakteristiğinin doğrudan değiştirilmesi ile sertliğin kontrol edilmesinin hedeflenmesidir. Bu sebeple yay karakteristiğini değiştirmek için aktif yay uzunluğunun değiştirilmesi prensibine dayanan bir tasarım mantığ benimsenerek bir mekanizma oluşturulmaya çalışılmış ve yaprak yay da bu mekanizma için en uygun seçim olmuştur. Bu amaçla tek bir elaman olarak kullanılan çıkış mili ve dişlisi birbirinden ayrımış ve dört adet konsol kirişli elastik bir kavrama mekanizması ile birbirine bağlanmıştır. Şekil 2 de gösterildiği gibi kavrama boyu sıfır olduğunda sistem rijit eyleyici olarak çalışmakta, kavrama boyu tasarımın izin verdiği en uzun boya ayarlandığında da ise eyleyici elastik eyleyici olarak görev yapmaktadır. Basit bir matematiksel model ile çıkış mili üzerindeki bu elastik kavramanın dönme rijitliği hesaplanmaya çalışılacaktır.

\subsection{Matematiksel Model}

Çıkış dişlisi ve çıkış mili birbirinden ayrı iki parça haline getirilmiş ve bu iki eleman birbirlerine dört adet yayrak yay ile bağlanmıştır. Mevcut tasarımda yapılan bu değişiklik Şekil 1 'de gösterilmektedir. Şekilden görüldüğü üzere dişli mekanizmasından gelen momenti alan son dişli üzerine yuvalar açılarak dört adet yaprak yay bu dişli üzerine konumlandırılmıştır. Momenti çıkışa ileten milin boyu uzatılarak alt kısmında yataklama için rulmanın oturabileceği çapta bir bölüm oluşturulmuştur. Bu kısım aynı zamanda konum ölçümü için potansiyometreye bağlıdır. Üst kısımda ise yaprak yayların bağlanacağı bir düzlem oluşturmak için çıkış milinin üzerine çıkış dişlisinin çap ölçüsünde silindirik bir kademe oluşturulmuştur. Oluşturulan bu bölümün mesafesi aktif yay uzunluğunun kısıtlarını belirlemektedir. Bu mekanizmada momenti ileten dişli düşey doğrultuda sabit olup, dişli mekanizmasından momenti alan çıkış mili aşağı yukarı hareket ederek aktif yay uzunluğunun değiştirilmesi sağlanmaktadır. Mekanizmanın sertlik ayarının sağlıklı şekilde yapılması için bir ayar mekanizması geliştirilerek hareketli dişli bu ayar mekanizmasının üzerine yataklanmıştır. Ayar mekanizmasının tasarımı Şekil 2‘de gösterilmektedir. Bu mekanizmada ayar kolu çevrildiğinde bağlı olduğu dişli dönmekte ve kremayer dişlide dairesel hareketi doğrusal harekete dönüşerek ayar mekanizması düşey doğrultuda hareket etmektedir. Bu mekanizma ile dişli ve çıkış mili birbirlerine yaprak yaylar ile elastik olarak bağlanmakta ve bu sayede sertliği değiştirilebilir bir kavrama mekanizması ortaya çıkmaktadır.

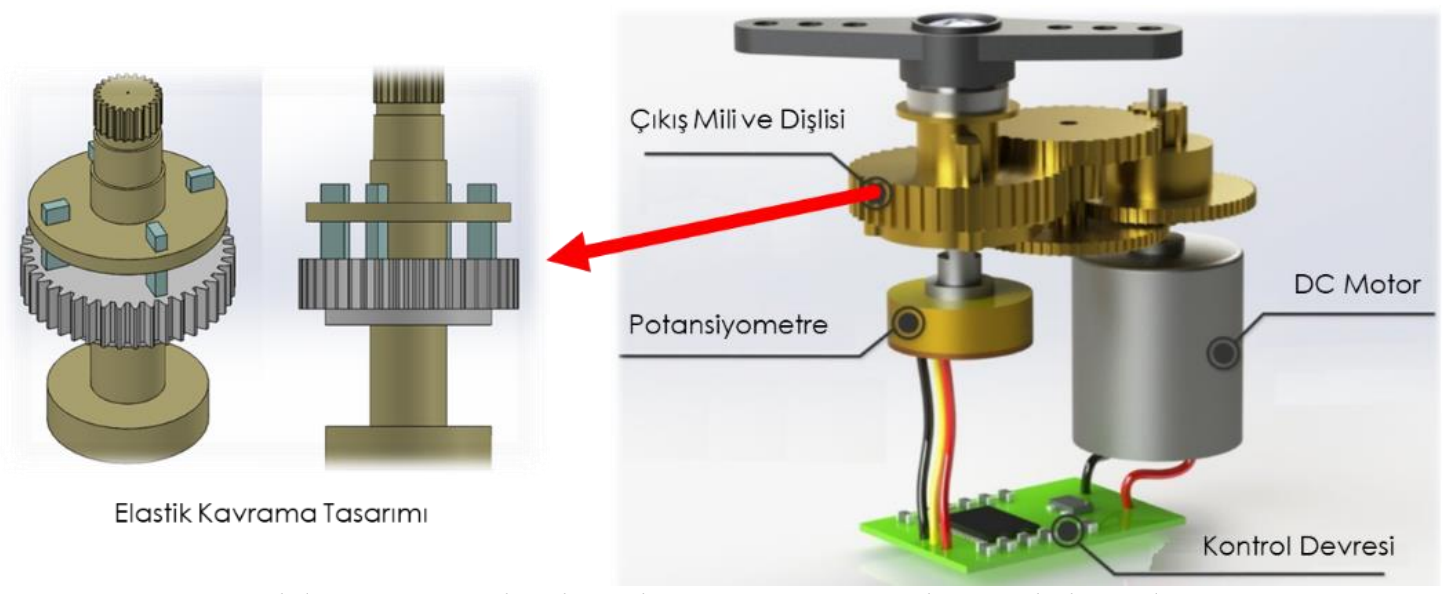

Şekil 1. Basit standart bir robot servosunun temel yapisal elemanlart 


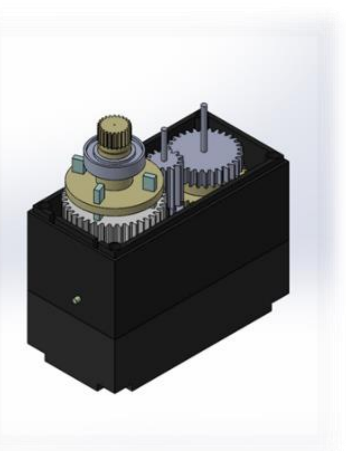

(a)

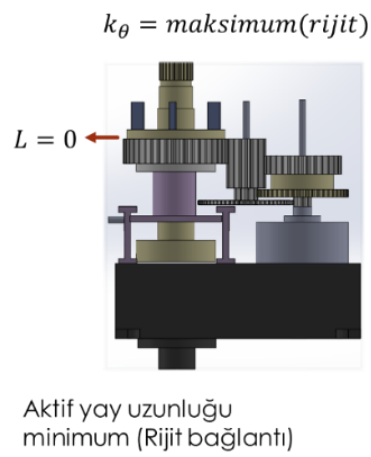

(b)

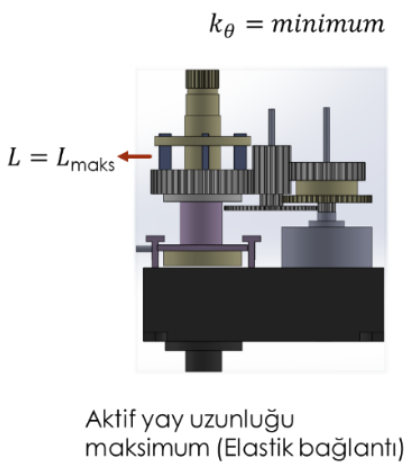

(c)

Şekil 2. Elastik eyleyicinin katı modeli ve kavrama uzunluğu ile sertlik kontrolü. a) Katı model, b) Minimum kavrama uzunluğu (rijit), c) Maksimum kavrama uzunluğu (maksimum elastik)

Sertliği değiştirilebilir eyleyici tasarımında kullanılan yaprak yaylar eğilmeye ve burulmaya zorlanmaktadır. Dolayısıyla sertlik ve dayanım değerleri için dairesel kesitli olamayan millerin eğilmesi ve burulması problemi incelenmelidir. Dairesel kesitli millerin burulması Coulomb'un yaptığı "Düzlem kesitler burulmadan sonra yine düzlem kalmaktadır." kabulü ile basit bir şekilde çözülebilmektedir. Burulmaya maruz dairesel olmayan çubuklarda ise düzlem kesitlerde çarpılmalar meydana gelmektedir. Dikdörtgen kesitli bir milin burulması Saint-Venant tarafından geliştirilen yarı ters metotla çözülmüştür [referans]. Dikdörtgen bir kesitte en büyük kayma gerilmesi eksene en yakın bulunan yüzeyin ortasında yani dikdörtgenin uzun kenarının ortasında meydana gelmekte olup Şekil 4 'te gösterilmektedir. Dikdörtgen kesitin köşeleri milin merkezine en uzak noktalardır. Eğer sınır şartları kullanılırsa bu noktalarda kayma gerilmelerinin sıfır olduğu görülmektedir. Dairesel kesitli millerde ise bu durumun aksine en büyük kayma gerilmeleri eksene en uzak noktalarda meydana gelmektedir. Dairesel kesitli olmayan millerin burulma hesapları dairesel kesitli millerin hesaplarından ayrı formüllerle hesaplanmaktadır. Dikdörtgen kesitli bir milin eğilme rijitliği Şekil 3 te gösterilen model üzerinden aşağıdaki gibi ifade edilebilir.

$$
k_{E}=\left(12 r^{2} E I\right) / L^{3}
$$

Burada, $k_{\mathrm{E}}$ dört adet yaprak yayın toplam eğilme rigitliğini, E elastisite modülünü, $I$ kesit atalet momentini, $r$ Prizmatik yayın orta noktasının dişli merkezinden uzaklığını ve $L$ aktif kavrama boyunu ifade etmektedir. Burulma problemi için ise Şekil 4 te gösterilen model üzerinden burulma rigitliği için aşağıdaki ifade türetilebilir;

$$
k_{B}=\left(4 \beta a b^{3} G\right) / L
$$

Burada, $k_{B}$ dört adet yaprak yayın toplam burulma rigitliğini, $G$ kayma modülünü, $\beta$ kesit oranı tesirini, $a, b$ kesit ölçülerini ve $L$ yine aktif kavrama boyunu ifade etmektedir. Denklemlerde kullanılan $\beta$ katsayıları için Çizelge 1 kullanılmaktadır.
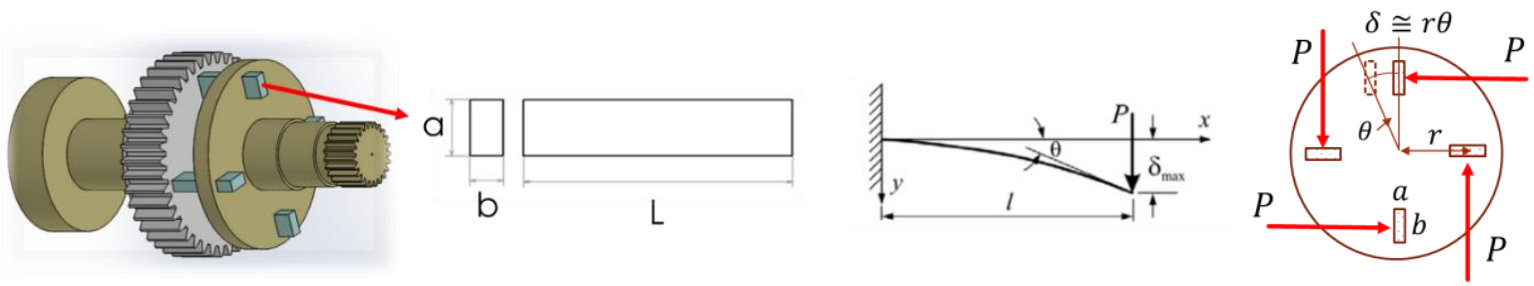

Şekil 3. Elastik kavramada elastik kirişlerin eğilme modeli

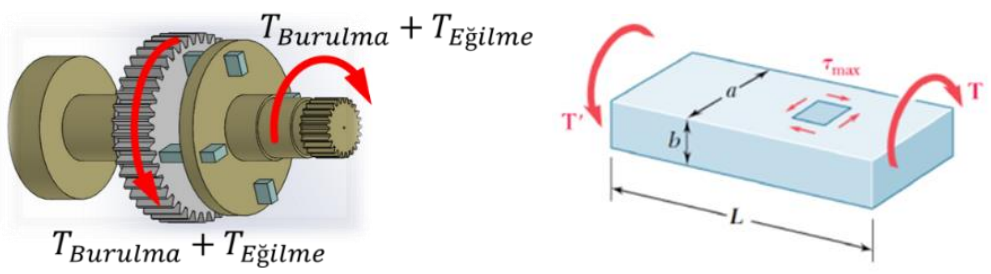

Şekil 4. Elastik kavramada elastik kirişleri burulma modeli

Tablo 1. $\alpha$ ve $\beta$ katsayılarl

\begin{tabular}{|c|c|c|c|c|c|c|c|c|c|c|c|}
\hline $\mathbf{a} / \mathbf{b}$ & $\mathbf{1 , 0}$ & $\mathbf{1 , 5}$ & $\mathbf{1 , 7 5}$ & $\mathbf{2 , 0}$ & $\mathbf{2 , 5}$ & $\mathbf{3 , 0}$ & $\mathbf{4 , 0}$ & $\mathbf{6 , 0}$ & $\mathbf{8 , 0}$ & $\mathbf{1 0 , 0}$ & $\infty$ \\
\hline $\boldsymbol{\beta}$ & 0,141 & 0,196 & 0,214 & 0,229 & 0,249 & 0,263 & 0,281 & 0,299 & 0,307 & 0,313 & 0,333 \\
\hline
\end{tabular}




\section{Analiz Sonuçları}

Denk. 1 ve 2 ile verilen bağıntılardan yararlanılarak eyleyicinin açısal sertlik değerleri kavrama uzunluğuna bağlı olarak elde edilebilmektedir. Yaprak yay (konsol kiriş) malzemesi olarak paslanmaz yay çeliği seçilmiş, yay çeliğinin elastisite modülü E=200 GPa, ve kayma modülü $\mathrm{G}=80 \mathrm{GPa}$ olarak belirlenmiştir. Yaprak yayın kesit yüksekliği $b=0,5 \mathrm{~mm}$ ve kesit genişiliği $a$ sırasıyla 3, 4 ve $5 \mathrm{~mm}$ olarak alınmaktadır. Bu ebatlar dikkate alondığında Çizelge 1'den $\beta$ değerleri sırası ile 0,229 - 0,307 ve 0,313 olarak okunabilir. Yaprak yayın toplam uzunluğu $L=8 \mathrm{~mm}$ olarak belirtilse de hesaplamalarda kullanılacak aktif yay uzunluğu tasarımdaki bağlantı ve hareket alanı kısıtlarından dolayı 0 ile 5mm arası değiştirilebilmektedir. Şekil 3 kavrama rijitliğinin kavrama boyu ile değişimini 1-5 mm aralığ için göstermektedir. Başlangıç pozisyonunda aktif yay uzunluğu $L=1$ olduğundan dolayı sert bir bağlantı halindeyken ikinci pozisyonda yani aktif yay uzunluğu $L=5 \mathrm{~mm}$ olduğunda eyleyici en yumuşak bağlantı pozisyonunda bulunmaktadır. Kirişin burulması ve eğilmesi problemi uzun kirişler için geçerli olduğu ve kavrama boyu sıfıra yaklaştıkça sertlik değerinin sonsuza yaklaşacağı açık olduğundan, analizlerde kavrama uzunluğu 1-5 mm aralığı için hesap edilmiştir. Bu sonsuzdan sıfıra yakınsayan bir eğrinin grafiksel okunabilirliğini sağlamak için özellikle yapılmış bir seçimdir.

Standart servo motorlarda boyutlar ve dişli geometrileri dikkate alındığında, servo motorun çıkış milinde azami tork değeri 2 Nm olarak değerlendirilebilir. Zira böylesi küçük boyutlardaki dişlilerin emniyetli olarak iletebilecekleri moment değeri sınırlıdır. Bu moment değeri dört adet birbirine paralel yaprak yay tarafından bölüşüleceği için her bir yaprak yayın maruz kalacağı değer moment 0,5 Nm olarak hesaplanabilir. Bu yükleme durumu için elastik mafsalın açısal yer değiştirmesinin kavrama boyu iledeğişimi Şekil 5 te veriliştir. Şekilden $2 \mathrm{Nm}$ lik azami çıkış momenti değerinde kesit genişliği 3, 4 ve 5 (mm) olarak seçilen yaprak yayların 5 mm lik maksimum kavrama boyu için sırasıyla $1,5^{\circ}, 2^{\circ}$ ve $2,5^{\circ}$ 'lik dönme esnekliği sağladığı görülmektedir.
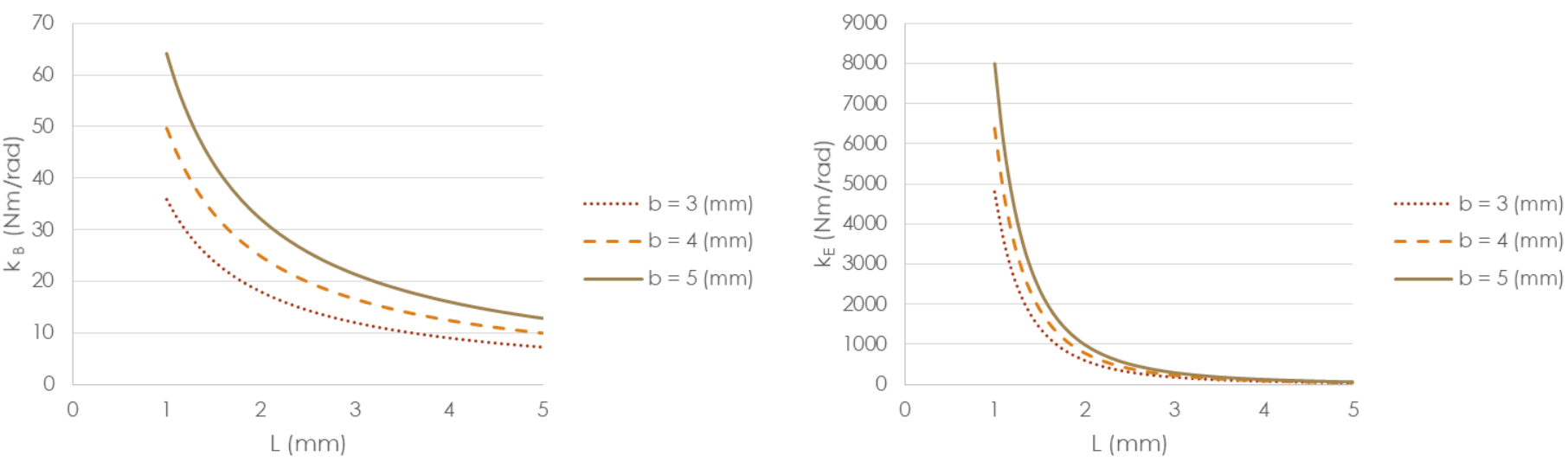

Şekil 4. Burulma ve eğilme sertliğinin kavrama boyu ile dĕ̆işimi. a.) Burulma, b.) Ĕ̆ilme
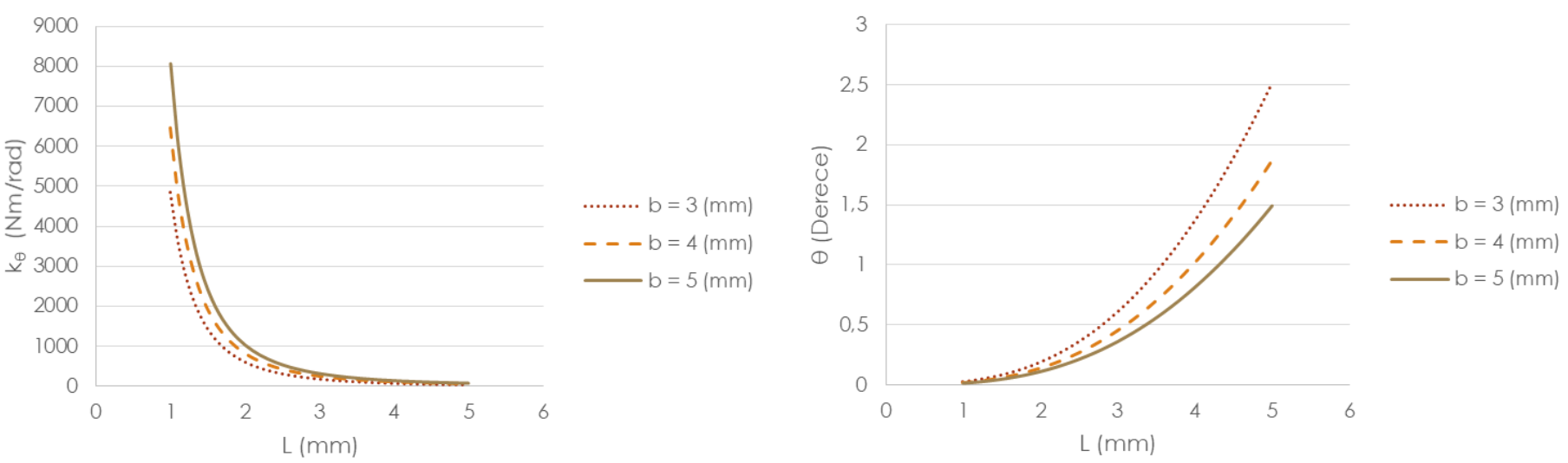

Şekil 5. a.) Eyleyici sertliğinin kavrama boyu ile değişimi (burulma+eğilme) b.) 2Nm Maksimum momentli standart robot servosu için maksimum esneme açısının kavrama boyu ile değişimi

\section{Tartışma}

$\mathrm{Bu}$ çalışmada, literatürdeki sertliği değiştirilebilir eyleyici tasarımları ve sertlik mekanizmaları incelenerek yeni bir sertliği değiştirilebilir eyleyici tasarımı oluşturulmuştur. Tasarımda yaprak yaylarda ortaya çıkan dairesel olmayan kesitlerin burulması ve eğilme problemi çözülerek eyleyicinin sertlik ve açısal deformasyon değerleri analitik olarak elde edilmiştir. Bu çalışmada tanıtılan elastik eyleyici, standart bir servo eyleyici temel alınarak ve ebatları değiştirilmeden oluşturulmuştur. Mevcut tasarımdaki sertlik değiştirme mekanizması elle kontrol edilen bir ayar cıvatasından oluşmaktadır. Bir başka deyişle sistem hareket halindeyken sertlik değiştirilemektedir. Ancak ayar koluna bir servo eyleyici bağlanarak, sistem hareket halindeyken de eyleyicinin sertlik değerini değiştirilebilecek bir tasarım elde edilebilmektedir. Mevcut çalışmada, eyleyicinin sertlik mekanizması tasarımına ve modellenmesine odaklanılmış olup sonraki çalışmalarda eyleyicinin kontrolü üzerine çalışmalar yapılması ve analitik hesaplamaların deneylerle 
doğrulanması hedeflenmektedir. Bu eyleyici tasarımının, sertliği değiştirilebilir eyleyicilerin yaygın bir şekilde kullanımına olanak tanıyacak basitlikte olması bakımından mevcut tasarımlara önemli bir alternatif olacağı düşünülmektedir.

\section{Teşekkür}

Elastik eyleyici tasarımın bilgisayar ortamında modellenmesi ve çizimlerinin oluşturulmasındaki yardımlarından dolayı değerli öğrencim İsmet Eralp Yüzük'e teşekkürlerimi sunarım.

\section{Kaynaklar}

Catalano, M., Grioli, G., Garabini, M., Bonomo, F., Mancini, M., Tsagarakis, N., \& Bicchi, A., (2011). Vsa-cubebot: a modular variable stiffness platform for multiple degrees of freedom robots, IEEE International Conference on Robotics and Automation, Shanghai, China, 5090-5095.

Hollander, K.W., Ilg R., Sugar, T.G., \& Herring, D., (2006). An efficient robotic tendon for gait assistance, Journal of Biomechanical Engineering, 128(5), 788-791.

Hurst, J.V., Chestnutt, J., \& Rizzi, A., (2004). An Actuator with Mechanically Adjustable Series Compliance, Carnegie Mellon University, USA, CMU-RI-TR- 04-24.

Jafari, A., Tsagarakis, N., Vanderborght, B., \& Caldwell, D., (2010). A novel actuator with adjustable stiffness (AwAS). IEEE/RSJ International Conference on Intelligent Robots and Systems, Taipei, Taiwan, 4201-4206.

Jafari, A., Tsagarakis, N., \& Caldwell, D.G., (2011). AwAS-II: A new actuator with adjustable stiffness based on the novel principle of adaptable pivot point and variable lever ratio, IEEE International Conference on Robotics and Automation, Shangai, China, 46384643.

Lee, C., Kwak, S., \& Oh, S., (2017). Generalization of Series Elastic Actuator Configurations and Dynamic Behavior Comparison, MDPI Actuators Journal. 1-26.

Migliore, S.A., Brown, E.A., \& De Weerth, S.P., (2005). Biologically inspired joint stiffness control, IEEE International Conference on Robotics and Automation, Spain, 4519-4524.

Pratt G.A., \& Williamson M., (1995). Series elastic actuators, IEEE International Workshop on Intelligent Robots and Systems, USA, 399-406.

Quy, H.V., Aryananda, L., Sheikh, F.I., Casanova F., \& Pfeifer, R., (2011). A novel mechanism for varying stiffness via changing transmission angle, IEEE International Conference on Robotics and Automation, Shanghai, China, 5076-5081.

Tonietti, G., Schiavi, R., \& Bicchi, A., (2005). Design and control of a variable stiffness actuator for safe and fast physical human/robot interaction. IEEE International Conference Robotics and Automation, Spain, 526-531.

Van Ham R., S. Thomas, B. Vanderborght, K. Hollander, \& D. Lefeber, (2009). Compliant actuator designs: review of actuators with passive adjustable compliance/controllable stiffness for robotic applications, IEEE Robotics and Automation Magazine 16(3), 8194.

Van Ham, R..,Vanderborght, B., Van Damme, M., Verrelst, B., \& Lefeber, D., (2007). MACCEPA, the mechanically adjustable compliance and controllable equilibrium position actuator: Design and implementation in a biped robot. Robotics and Autonomous Systems, 55(10), 761-768.

Vanderborght, B., Albu-Schaeffer, A., Bicchi, A., Burdet, E., Caldwell, D., \& Carloni, R., (2013). Variable impedance actuators: A review, Robotics and Autonomous Systems, 61(12), 1601-1614.

Vanderborght B., A. Albu-Schaeffer, A. Bicchi, E. Burdet, D. Caldwell, R. \& Carloni, M. (2012), Variable Impedance Actuators: Moving the Robots of Tomorrow, IEEE/RSJ International Conference on Intelligent Robots and Systems, Algarve, Portugal, 5454-5455.

Wolf, S., Hirzinger, G., (2008). A new variable stiffness design: Matching requirements of the next robot generation. IEEE International Conference on Robotics and Automation, California, USA, 1741-1746. 